\title{
A Study on Job Satisfaction, Stressors and Job Burnout of Nurses in a Third-Class Hospital in Haikou
}

\author{
Lihua Wu' ${ }^{1}$, Shuping Zhou ${ }^{2 *}$, Yunsuo Gao², Xiaodan Wang ${ }^{3}$ \\ ${ }^{1}$ The Second Affiliated Hospital of Hainan Medical University, Haikou, China \\ ${ }^{2}$ Hainan General Hospital, Haikou, China \\ ${ }^{3}$ School of Public Health, Hainan Medical University, Haikou, China \\ Email: `ZSPLJH@163.com
}

How to cite this paper: $\mathrm{Wu}, \mathrm{L} . \mathrm{H} ., \mathrm{Zhou}$, S.P., Gao, Y.S. and Wang, X.D. (2021) A Study on Job Satisfaction, Stressors and Job Burnout of Nurses in a Third-Class Hospital in Haikou. Open Journal of Nursing, 11, 600-609.

https://doi.org/10.4236/ojn.2021.117051

Received: March 25, 2021

Accepted: July 20, 2021

Published: July 23, 2021

Copyright $\odot 2021$ by author(s) and Scientific Research Publishing Inc. This work is licensed under the Creative Commons Attribution International License (CC BY 4.0).

http://creativecommons.org/licenses/by/4.0/

\begin{abstract}
Objective: With the development of society, people's requirements and standards for nursing work continue to improve, under the premise of nursing human resources are relatively insufficient, nursing work from nursing skills to service attitude to ensure quality, this standard brings great work pressure to nursing staff, in addition, the increasing medical disputes, It increases the risk factor of personal safety attack in the workplace of nurses, and further increases the psychological pressure of nurses, thus increasing the incidence of job burnout of nurses. Methods: A multi-stage random sampling was adopted to conduct a questionnaire survey among 1049 nursing staff on December 1, solstice and December 30, 2015. The current situation of nurses' job satisfaction, stressors and job burnout and its influencing factors were analyzed. Results: 1 ) The total score of nurses' job satisfaction was $91.52 \pm$ 17.99 points; 2) The total score of nurses' work stressors was $86.52 \pm 21.95$ points; 3) The total score of nurses' job burnout was $38.44 \pm 7.55$ points; 4 ) The aspects of patient care, management and interpersonal relationship were significantly correlated with nurses' burnout $(\mathrm{P}<0.001)$, and the total score of job satisfaction was positively correlated with nurses' burnout, while the total score of job satisfaction was negatively correlated with nurses' burnout. There was a significant correlation between job title and nurse burnout $(\mathrm{P}<$ 0.001). Conclusion: The job burnout of nurses is related to nurse satisfaction and work pressure. The problems of management and interpersonal relationship, title, total score of job satisfaction and patient care are the main problems of nurses' job burnout.
\end{abstract}




\section{Keywords}

Job Burnout, Current Situation Analysis, Influencing Factors, Nurses

\section{Introduction}

The nursing profession is a professional and technical profession, which is characterized by the combination of mental and physical labor, high risk of work, etc., coupled with the current tension between health care and patients, may suffer from the threat of violence in the workplace [1], and the nursing staff is under great pressure. Job burnout is a serious negative emotional state that individuals in the profession who serve people fall into, with a high incidence rate among nurses [2] [3] [4] [5]. With the progress of the society, the requirements and standards for nurses are constantly improved, which often increases the occupational pressure of nurses. Under the influence of these pressures, not only the work enthusiasm of nurses will be reduced, but also the incidence of burnout of nurses will be increased [6]. Surveys show that nurses' job satisfaction is related to turnover intention, which is an important intermediary variable of nurses' turnover. Low job satisfaction can lead to high turnover intention of nurses [7]. This study analyzed the current situation of nurses' job satisfaction, stress sources and job burnout in the third-grade A hospital of Haikou City, and put forward effective suggestions for improving nursing job satisfaction and alleviating the situation of nurses' job burnout.

\section{Objects and Methods}

\subsection{Subjects}

The multi-stage random sampling method was adopted for sampling on December 1, 2015. Three hospitals were selected by simple random sampling method. The nurses in each hospital were divided into 7 levels: internal, external, gynographic, pediatric, emergency, intensive care unit and outpatient department. Equal proportion stratified random sampling method was adopted, and $50 \%$ of the nurses from each level were selected. Inclusion and exclusion criteria: Inclusion criteria were engaged in clinical nursing work, voluntary participation in the study, age $\geq 30$ years old; exclusion criteria were secondment to a non-nursing post for a total of more than 5 years.

\subsection{Methods}

\subsubsection{Survey Tools}

1) General questionnaire: including age, gender, professional title, educational background, etc.

2) Nurse Job Satisfaction Scale: The McCloskey/Mueller Satisfaction Scale (MMSS) is the most widely used and has been proved to have good reliability and validity. A total of 31 items are included in 8 aspects, including welfare ben- 
efits, scheduling, family and work balance, relationship between colleagues, social opportunities, part-time job opportunities, job recognition, professional development, and control and responsibility over work [8].

3) Nurse work stress scale: The scale was divided into 5 aspects with a total of 35 items, including 7 questions about nursing profession and work. There are five problems of time allocation and workload [9]. Insufficient working environment and instruments and equipment have 3; there were 11 problems with patient care; there are nine problems of management and interpersonal relationship [10]. Grade 1 - 4 scoring method was adopted, and the higher the score, the greater the pressure [11].

4) Nursing Burnout Scale (NBS): There were 3 dimensions of emotional exhaustion, depersonalization and sense of achievement, with 15 items, and the scoring method was used from 1 to 5 . The scores of the three dimensions are independent of each other and cannot be added. The scores of each dimension are the average scores of all the items in this dimension. The higher the scores on emotional exhaustion and depersonalization, the higher the burnout; the higher the score on less achievement, the lower the burnout.

\subsubsection{Data Collection}

The questionnaire survey lasted for one month from December 1, 2015. The head nurse of the investigation department organized and coordinated the issuance of questionnaires, and completed the survey according to the requirements to ensure the authenticity and integrity of the questionnaire. It took about 20 minutes to complete the questionnaire by oneself. 5 items missing > will be removed. A total of 1100 questionnaires were sent out, and 1049 valid questionnaires were collected after eliminating incomplete ones, with an effective recovery of $93.36 \%$.

\subsection{Statistical Analysis}

After the data were collected, the data were coded, quantized and assigned, and then double data entry was performed with EpiData3.0. SPSS19.0 statistical software was used for statistical analysis. Mean and standard deviation were used to describe the measurement data, and relative numbers were used to describe the enumeration data. The measurement data of the two groups and above were compared by ANOVA, and the influencing factors were studied by multiple linear regression method. The test level was 0.05 .

\section{Results}

\subsection{General Information of the Subjects}

A total of 1049 subjects were included, including 31 males and 1018 females, with a male to female ratio of 3:97. The average age was $37.98 \pm 7.32$ years old, and the average nursing age was $17.05 \pm 8.41$ years old. The analysis of the professional title of nurses showed that there were a total of 1049 nursing staff, in- 
cluding 91 nurses (8.7\%), 364 nurses (34.7\%), 478 in charge nurses (45.6\%) and 116 deputy chief nurses or above (11.1\%).

\subsection{The Total Score of Job Satisfaction, Job Stress Sources, Job Burnout and Scores of Various Dimensions of Nurses in Third-Grade A Hospitals of Haikou City}

\subsubsection{Score of Nurses' Job Satisfaction in Various Dimensions}

The total score of nurses' job satisfaction was $91.52 \pm 17.99$ points, and the scores of each dimension were shown in Table 1.

\subsubsection{Comparison of Different Dimensions of Nurses' Job Satisfaction in Different Hospitals}

By analysis of variance, the different hospital nurses job satisfaction each dimension scores are compared, the results of the analysis show that the professional development and control of the work and responsibilities, for the scheduling of satisfaction, the relationship between colleagues and the management pattern, work to be recognized, the balance of family and work in 4 hospitals, $\mathrm{P}$ values were less than 0.05 , statistically significant, It shows that there are differences in professional development, control and responsibility of work, satisfaction with scheduling, relationship between colleagues and management mode, recognition of work, family and work among four hospitals. The P value of the total score of job satisfaction of the four hospitals was greater than 0.05 , which was not statistically significant. The pairwise comparison was made by SNK method, and the results were shown in Table 2.

\subsubsection{The Scores of Various Dimensions of Nurses' Work Stressors}

The total score of nurses' work stressors was $86.52 \pm 21.95$ points, and the scores of each dimension were shown in Table 3.

\subsubsection{Comparison of Scores of Different Dimensions of Nurses' Work Stressors in Different Units}

By analysis of variance, the hospital nurse work pressure source different dimension scores are compared, the results of the analysis show that problems in

Table 1. Scores of nurses' work satisfaction.

\begin{tabular}{cc}
\hline The dimension & $(\bar{x} \pm s)$ \\
\hline $\begin{array}{c}\text { Control and responsibility for work } \\
\text { Satisfaction with scheduling }\end{array}$ & $25.39 \pm 6.62$ \\
Relationships and management patterns among colleagues & $17.42 \pm 4.88$ \\
Social opportunities & $14.80 \pm 2.71$ \\
Welfare treatment & $10.35 \pm 3.15$ \\
Recognized for work & $8.65 \pm 2.53$ \\
Opportunities for part-time work & $10.49 \pm 2.16$ \\
Family/work balance & $2.26 \pm 1.07$ \\
Total job satisfaction score & $2.15 \pm 1.03$ \\
\hline
\end{tabular}


Table 2. Comparison of work satisfaction degree of nurses in different hospitals $(\bar{x} \pm s)$.

\begin{tabular}{|c|c|c|c|c|c|c|}
\hline & $A(n=391)$ & $\mathrm{B}(\mathrm{n}=211)$ & $\mathrm{C}(\mathrm{n}=197)$ & $\mathrm{D}(\mathrm{n}=250)$ & $F$ & $P$ \\
\hline $\begin{array}{l}\text { Control and } \\
\text { Responsibility }\end{array}$ & $25.36 \pm 6.36^{\mathrm{b}}$ & $26.22 \pm 7.40^{\mathrm{b}}$ & $26.54 \pm 6.04^{\mathrm{b}}$ & $23.81 \pm 6.48^{\mathrm{a}}$ & 8.01 & $<0.01$ \\
\hline $\begin{array}{l}\text { Satisfaction with } \\
\text { scheduling }\end{array}$ & $16.73 \pm 4.84^{\mathrm{a}}$ & $17.74 \pm 5.54^{\mathrm{b}}$ & $17.91 \pm 4.51^{\mathrm{b}}$ & $17.83 \pm 4.54^{\mathrm{b}}$ & 4.19 & 0.01 \\
\hline Social opportunities & $10.28 \pm 3.20$ & $10.29 \pm 3.32$ & $10.71 \pm 3.06$ & $10.25 \pm 3.00$ & 1.03 & 0.38 \\
\hline Welfare treatment & $8.45 \pm 2.58^{\mathrm{a}}$ & $8.93 \pm 2.85^{\mathrm{b}}$ & $8.96 \pm 2.44^{\mathrm{b}}$ & $8.49 \pm 2.16^{\mathrm{ab}}$ & 3.04 & 0.03 \\
\hline $\begin{array}{l}\text { Relationships and } \\
\text { management } \\
\text { patterns among } \\
\text { colleagues }\end{array}$ & $15.06 \pm 2.68^{\mathrm{a}}$ & $15.26 \pm 2.78^{\mathrm{a}}$ & $14.29 \pm 2.76^{\mathrm{b}}$ & $14.40 \pm 2.53^{\mathrm{b}}$ & 7.57 & $<0.01$ \\
\hline $\begin{array}{l}\text { Recognized } \\
\text { for work }\end{array}$ & $10.61 \pm 2.02^{\mathrm{b}}$ & $10.64 \pm 2.28^{\mathrm{b}}$ & $10.05 \pm 2.24^{\mathrm{a}}$ & $10.52 \pm 2.16^{\mathrm{b}}$ & 3.51 & 0.02 \\
\hline $\begin{array}{l}\text { Opportunities for } \\
\text { part-time work }\end{array}$ & $2.16 \pm 1.07$ & $2.31 \pm 1.15$ & $2.37 \pm 1.07$ & $2.30 \pm 1.02$ & 2.12 & 0.10 \\
\hline $\begin{array}{l}\text { Family/work } \\
\text { balance }\end{array}$ & $2.05 \pm 0.998^{\mathrm{a}}$ & $2.19 \pm 1.06^{\mathrm{b}}$ & $2.31 \pm 1.10^{\mathrm{ab}}$ & $2.16 \pm 0.98^{\mathrm{ab}}$ & 3.07 & 0.03 \\
\hline $\begin{array}{c}\text { Total job } \\
\text { satisfaction score }\end{array}$ & $90.1 \pm 17.94$ & $93.59 \pm 20.1$ & $93.14 \pm 16.7$ & $89.76 \pm 16.94$ & 2.54 & 0.06 \\
\hline
\end{tabular}

Note: ab represents a data subset, and the same letter indicates that there is no statistically significant difference in the population mean of each group; otherwise, it is statistically significant.

Table 3. Scores of nurses' work pressure.

\begin{tabular}{ccc}
\hline number & dimension & $\bar{x} \pm s$ \\
\hline 1 & Problems in patient care & $29.21 \pm 7.93$ \\
2 & Management and interpersonal problems & $19.08 \pm 6.98$ \\
3 & nursing professional and work problems & $17.59 \pm 4.91$ \\
4 & Time allocation and workload problems & $13.44 \pm 4.07$ \\
5 & Problems of working environment and equipment & $7.20 \pm 2.78$ \\
6 & Total score of working pressure sources & $86.52 \pm 21.95$ \\
\hline
\end{tabular}

nursing profession and work, time allocation and workload, work environment and equipment problems, patient care issues in 4 hospitals, $\mathrm{P}$ values were less than 0.05 , statistically significant, it is explained that there are differences among the four hospitals in nursing specialty and working problems, time allocation and workload problems, working environment and equipment problems, and patient care problems. The $\mathrm{P}$ value of the total score of work stress sources in the four hospitals was less than 0.05 , which was statistically significant. The pair-for-pair-comparison was performed by SNK method, and the results were shown in Table 4.

\subsubsection{Scores of Nurses' Job Burnout in Various Dimensions}

The total score of nurses' job burnout was $38.44 \pm 7.55$ points, and the scores of 
Table 4. Comparison of scores of nurses' work pressure sources in different units.

\begin{tabular}{ccccccc}
\hline dimension & $\mathrm{A}(\mathrm{n}=391)$ & $\mathrm{B}(\mathrm{n}=211)$ & $\mathrm{C}(\mathrm{n}=197)$ & $\mathrm{D}(\mathrm{n}=250)$ & $F$ & $P$ \\
\hline $\begin{array}{c}\text { Nursing } \\
\text { professional } \\
\text { and work related } \\
\text { problems }\end{array}$ & $17.83 \pm 4.70^{\mathrm{a}}$ & $18.11 \pm 5.35^{\mathrm{a}}$ & $16.73 \pm 4.67^{\mathrm{a}}$ & $17.45 \pm 4.98^{\mathrm{ab}}$ & 3.241 & 0.021 \\
$\begin{array}{c}\text { Time allocation and } \\
\text { workload issues }\end{array}$ & $14.43 \pm 3.91^{\mathrm{b}}$ & $13.17 \pm 4.36^{\mathrm{a}}$ & $12.78 \pm 3.79^{\mathrm{a}}$ & $12.64 \pm 3.99^{\mathrm{a}}$ & $13.38<0.001$ \\
$\begin{array}{c}\text { Working } \\
\text { environment } \\
\text { and equipment } \\
\text { problems }\end{array}$ & $8.03 \pm 2.69^{\mathrm{d}}$ & $5.96 \pm 2.69^{\mathrm{a}}$ & $6.77 \pm 2.65^{\mathrm{b}}$ & $7.28 \pm 2.66^{\mathrm{c}}$ & $29.43<0.001$ \\
$\begin{array}{c}\text { Patient care issues } \\
\begin{array}{c}\text { Management and } \\
\text { interpersonal } \\
\text { problems }\end{array}\end{array}$ & $30.30 \pm 7.51^{\mathrm{b}}$ & $28.66 \pm 8.43^{\mathrm{b}}$ & $27.05 \pm 7.69^{\mathrm{a}}$ & $29.67 \pm 8.00^{\mathrm{b}}$ & $8.142<0.001$ \\
$\begin{array}{c}\text { Total score of } \\
\text { working stressors }\end{array}$ & $89.56 \pm 20.90^{\mathrm{b}}$ & $84.62 \pm 23.76^{\mathrm{a}}$ & $82.72 \pm 21.52^{\mathrm{a}}$ & $86.35 \pm 21.77^{\mathrm{ab}}$ & 5.064 & 0.002 \\
\hline
\end{tabular}

Note: ab represents a data subset, and the same letter indicates that there is no statistically significant difference in the population mean of each group; otherwise, it is statistically significant.

Table 5. Scores of nurses' job burnout.

\begin{tabular}{cc}
\hline dimension & $(\bar{x} \pm s)$ \\
\hline Emotional exhaustion & $20.17 \pm 5.13$ \\
Less a sense of accomplishment & $12.54 \pm 3.83$ \\
To personalize & $5.73 \pm 2.47$ \\
Total burnout score & $38.44 \pm 7.55$ \\
\hline
\end{tabular}

each dimension were shown in Table 5.

\subsubsection{Comparison of Scores of Various Dimensions of Nurses' Burnout in Different Units}

Variance analysis was used to compare the scores of nurses' job burnout in various dimensions in different hospitals. The analysis results showed that the $\mathrm{P}$ values of emotional exhaustion, low sense of achievement and depersonalization were all less than 0.05 in the four hospitals, which was statistically significant, indicating that there were differences in emotional exhaustion, low sense of achievement and depersonalization among the four hospitals. The $\mathrm{P}$ value of the total score of job burnout in the four hospitals was less than 0.05 , which was statistically significant. The pairwise comparison was made by SNK method, and the results are shown in Table 6.

\subsubsection{Multiple Linear Regression Analysis}

Job burnout score as Y, job satisfaction, work the pressure source, total score of five dimensions, employment status, personal income before tax, title, position, in the work has met the medical alarm or medical violence, family savings and 
Table 6. Scores of nurses' job burnout in different units.

\begin{tabular}{ccccccc}
\hline dimension & $\mathrm{A}(\mathrm{n}=391)$ & $\mathrm{B}(\mathrm{n}=211)$ & $\mathrm{C}(\mathrm{n}=197)$ & $\mathrm{D}(\mathrm{n}=250)$ & $F$ & $P$ \\
\hline $\begin{array}{c}\text { Emotional } \\
\text { exhaustion }\end{array}$ & $21.0 \pm 5.03^{\mathrm{b}}$ & $20.41 \pm 5.63^{\mathrm{b}}$ & $19.17 \pm 4.51^{\mathrm{a}}$ & $19.37 \pm 5.06^{\mathrm{a}}$ & 8.66 & $<0.001$ \\
$\begin{array}{c}\text { Less a sense of } \\
\text { accomplishment }\end{array}$ & $12.39 \pm 3.78^{\mathrm{a}}$ & $12.44 \pm 3.65^{\mathrm{a}}$ & $13.80 \pm 3.76^{\mathrm{b}}$ & $11.88 \pm 3.91^{\mathrm{a}}$ & 10.03 & $<0.001$ \\
$\begin{array}{c}\text { To personalize } \\
\begin{array}{c}\text { Total burnout } \\
\text { score }\end{array}\end{array}$ & $5.73 \pm 2.57^{\mathrm{a}}$ & $5.68 \pm 2.43^{\mathrm{a}}$ & $6.40 \pm 2.50^{\mathrm{b}}$ & $5.24 \pm 2.23^{\mathrm{a}}$ & 8.23 & $<0.001$ \\
& & $38.53 \pm 8.00^{\mathrm{b}}$ & $39.37 \pm 6.98^{\mathrm{b}}$ & $36.49 \pm 7.48^{\mathrm{a}}$ & 7.91 & $<0.001$ \\
\hline
\end{tabular}

Note: $a b$ represents a data subset, and the same letter indicates that there is no statistically significant difference in the population mean of each group; otherwise, it is statistically significant.

Table 7. Multiple linear regression analysis of job burnout of nurses in third-grade hospitals of Haikou City.

\begin{tabular}{cccccc}
\hline factors & B & Error & Beta & t-value & P value \\
\hline $\begin{array}{c}\text { Management and } \\
\text { interpersonal problems }\end{array}$ & 0.213 & 0.043 & 0.197 & 4.956 & $<0.001$ \\
The title & -0.988 & 0.273 & -0.105 & -3.614 & $<0.001$ \\
$\begin{array}{c}\text { Nursing professional and } \\
\text { work related problems }\end{array}$ & 0.100 & 0.061 & 0.065 & 1.647 & 0.100 \\
$\begin{array}{c}\text { Total job satisfaction score } \\
\text { Patient care issues }\end{array}$ & -0.033 & 0.014 & -0.080 & -2.371 & 0.018 \\
\hline
\end{tabular}

property situation as independent variables, multiple linear regression analysis, the factors leading to the regression equation with management and interpersonal problems, professional titles, the results of the total score of job satisfaction and the problems in patient care are shown in Table 7.

\section{Discussion}

1) Nurses' job satisfaction, stress sources and job burnout

Nurses, as front-line clinical staff, are one of the most important components of hospitals and the main force of the development of nursing cause. Their work enthusiasm directly affects the quality of nursing and organizational development [12]. There are differences in the balance between several dimensions of professional development and control and responsibility for work, satisfaction with scheduling, social opportunities, relationships with colleagues and management patterns, work recognition, and family and work. Nursing specialty and work issues, time allocation and workload issues, working environment and equipment issues, and patient care issues varied among the four hospitals. Emotional exhaustion, less achievement, and depersonalization varied among the four hospitals and the level of burnout varied between the four hospitals. Grade-A hospitals are the places where patients with difficult and critical conditions are treated. Patients' conditions are prone to change, there are more difficult nursing operations, and they also face the pressure of night shifts. Therefore, 
the reason for this difference may be that the nursing work in third-grade hospitals is very heavy and stressful, which is easy to cause dissatisfaction and job burnout [13]. This is consistent with the findings of Wang Xia [14], which may be related to the size of the hospital and the number of visits. The larger the hospital scale, the larger the number of visits, and the higher the level of job burnout. The specialized medical characteristics of each hospital are not the same, so the diseases treated are different, and the nursing workload of nurses is also different. Therefore, each hospital should reasonably arrange nursing human resources according to the patient condition and nursing workload of its own hospital, and do a good job in nursing monitoring of weak links. Income is the guarantee of family life, nursing work load, but the salary does not really reflect the value of nursing. Studies have found that dissatisfaction with income is one of the reasons why more nurses quit [15]. Therefore, the first strategy to improve nurses' job satisfaction is to scientifically evaluate the value of nursing services and establish a fair and reasonable salary system based on the nursing workload [16].

2) The results of multiple linear regression analysis show that the factors entering the regression equation include management and interpersonal problems, professional title, and total job satisfaction score. Management and interpersonal aspects are positively correlated with the total scores of nurses and job burnout, which is consistent with the research results of Wan Min [17]. Good management methods and interpersonal relationships can make nurses have positive psychology, recognition of their own work ability and increase confidence. The total score of job satisfaction is negatively correlated with the job burnout of nurses. The higher the job satisfaction of nurses is, the lower the job burnout is, which is consistent with the research results of Yu Yanlin [18] and Huang Can [19] et al. Moderate improvement of nurses' treatment, increase of welfare, as far as possible to reduce or remove the work outside the scope of nurses, learning content, improve the conditions of the working environment and so on, improve the nurse's comfort, reduce dissatisfaction, can improve the nurse's job satisfaction.

Professional title is significantly correlated with nurses' job burnout, which is the same as the research of Tian Jin et al. [20]. The job burnout of nurses with different professional titles is different, which is consistent with the survey results of $\mathrm{Wu}$ Dequan [21]. This may be related to the working years and experience of nurses with different professional titles, as well as the psychological pressure they bear, and the different degree of work risk and responsibility they undertake. Nurses have short working life, lack of nursing experience for all kinds of acute and critical patients, and have weak psychological bearing capacity. Nurses and deputy director of the nurse and above, all through a variety of nursing professional training, in clinical practice has a wealth of practice, have a strong nursing work and psychological endurance. To give nursing staff more promotion channels of professional title, remove unnecessary conditions for professional title promotion, and give nursing staff more promotion opportuni- 
ties can effectively reduce the incidence of nurses' job burnout.

3) Suggestion

According to nurses' job satisfaction, job pressure sources and job burnout, hospitals should establish a fair talent performance mechanism and a sound training mechanism, so that nurses can get equal opportunities for training and continuing education and constantly find confidence in their career development [20]. Hospitals should strengthen organizational efforts, adopt humanized management, pay attention to the physical and mental health of medical staff, strengthen the communication and exchange between management staff and clinical nurses, improve the satisfaction of nurses, and ensure the stability of nursing team [22].

\section{Limitations}

This study only focused on nurses in internal, external, gynographic, pediatric, emergency, intensive care unit and outpatient department in the tertiary Grade A general hospital of Haikou City, which was limited in terms of region and not representative of other regions of the country. On a national level, more studies are needed in different areas. At the same time, this study was limited to nurses in tertiary general hospitals, and nurses in hospitals such as second class A and county level hospitals were not included in the study, which could not fully reflect the real situation related to job burnout of nurses in medical institutions at all levels in China. More studies on job burnout of medical nurses at all levels need to be further supplemented.

\section{Conflicts of Interest}

The authors declare no conflicts of interest regarding the publication of this paper.

\section{References}

[1] Atan, S., Arabaci, L.B., Sirin, A., et al. (2013) Violence Experienced by Nurses at Six University Hospitals in Turkey. Journal of Psychiatric and Mental Health Nursing, 20, 882-889. https://doi.org/10.1111/jpm.12027

[2] Li, L., Ruan, H., Jiang, H., Wang, H.F. and Yang, Y.L. (2013) Study on the Influencing Factors of Job Burnout of ICU Nurses in Five Tertiary and First-Class General Hospitals in Shanghai. Nursing Management in China, No. 11, 48-51.

[3] Tang, Y., Ding, W. and Chen, J.F. (2013) Investigation on Occupational Burnout of Nurses in Tertiary A Hospitals in Ningxia. Qilu Nursing Journal, No. 24, 4-5.

[4] Fu, G.L. and Chen, W.J. (2013) Study on the Relationship between Night Shift and Job Burnout of Nurses in Third-Class Hospitals. Journal of Nurses Continuing, No. 7, 637-639.

[5] Wu, X.P. (2013) Investigation on Working Stress and Mental Health Status of Nurses in Wards of a Third-Class A Hospital. Chinese Medicine Guide, No. 36, 293-294.

[6] Wang, L.H., Xi, M.X. and Li, D. (2012) Investigation on Job Burnout of Nurses with Different Technical Titles. Chinese and Foreign Medical Care, No. 12, 18-19+21. 
[7] Lv, L., Li, G.H. and Chen, H.Y. (2016) Research Progress on the Correlation between Nursing Practice Environment and Nurse Turnover. China Hospital, 20, 73-75.

[8] Zhu, M. (2014) Investigation and Analysis of Nurses' Career Satisfaction in Holistic Nursing Ward with Responsibility System. Chinese Medical Guide, No. 4, 262-263.

[9] Lin, S.L., Huang, X.F. and Zhou, R.F. (2010) Relationship Analysis of Nurses' Job Burnout and Work Stress Sources. Nursing and Rehabilitation, No. 2, 102-103+105.

[10] Jiang, Y.Q., Dong, J. and Tang, F.R. (2013) Influence of Quality Nursing Service Demonstration Project on Working Stress and Job Burnout of Nurses. Journal of Hospital Management of the PLA, No. 8, 80-82.

[11] Li, C.G., Tian, X.H., Feng, L.N. and Zhang, R. (2014) Study on the Correlation between Work Stress, Coping Style and Job Burnout of Nurses in Intensive Care Unit. Nursing Research, No. 26, 40-41.

[12] Liu, Z.Y., Hu, Y.L., Wei, W.H., et al. (2016) The Influence of Job Satisfaction on Civic Organizational Behavior of Nurses. Modern Preventing Medicine, 43, 3387-3390.

[13] Wang, S.H., Sun, M.H., Gao, H.P., et al. (2011) Relationship between Job Stress Coping and Job Burnout in Nurses. Nursing Practice and Research, 8, 16-18.

[14] Wang, X. (2006) Study on the Correlation between Nurses' Job Burnout and Nurses' Working Environment in Changsha. Central South University, Changsha.

[15] Song, C.P., Feng, H., Sun, X.L., et al. (2015) Current Situation and Influencing Factors of Clinical Nursing Turnover Intention. Nursing Journal of PLA, 32, 42-45.

[16] Zheng, X.J. (2009) Study on the Status Quo and Influencing Factors of Nurses' Job Satisfaction in Beijing Tertiary General Hospital. Peking Union Medical College, Beijing.

[17] Wan, M. (2011) Investigation and Analysis of Nurse Burnout Factors. Chinese Community Physician (Medical Professional), 13, 182-183.

[18] Yu, Y.L. (2013) Study on Job Burnout and Job Satisfaction of Nursing Staff. Journal of Traditional Chinese Medicine Management, 21, 313-315.

[19] Huang, C. and Peng, Y.Z. (2017) Analysis of Occupational Burnout Status of Medical Staff and Its Influencing Factors: A Case Study of a Class A General Hospital in Jiangsu Province. Journal of Jiangsu Normal University (Philosophy and Social Sciences Edition), 43, 88-98.

[20] Tian, J. and Zhang, S. (2018) Analysis of Job Burnout Status and Influencing Factors of 330 Medical Staff in a Hospital. Chongqing Medical Journal, 47, 3685-3688.

[21] Wu, D.Q., Wu, D. and Zhang, M. (2015) Study on the Relationship between Job Burnout and Job Stress, Job Satisfaction and Social Support of Nurses in New Hospitals. General Practice, No. 35, 3529-3532.

[22] Nie, Z.H., Yu, J.G., He, L.P., Jin, Y.L., Chen, Y., Guo, D.X., Ren, X.H., Wang, L.H. and Yao, Y.S. (2015) Journal of Yangtze University (Natural Science Edition), 12, $112-114+5$. 